\title{
Die kerk se korporatiewe identiteit ${ }^{1}$
}

\author{
Johan Buitendag \\ Departement Dogmatiek en Christelike Etiek \\ Universiteit van Pretoria
}

\begin{abstract}
The church's corporate identity

This article investigates the rather unknown theme of "corporate identity and corporate image" as applied to the church. Starting from the premise that corporate identity enables us to communicate change, direction and a church's point of difference, it is evident that proper strategic and visionary management is a prerequisite for the church today. "Corporate image is in the eyes of the world" and this urges the church to regard this undertaking in a serious light. Thus, a church's unique selling proposition has to be identified, not necessarily to compete, but to add specific value for its members. The concept of "sur/petition" of Edward de Bono (vis-à-vis competition) is pursued in an integrated value system. The article addresses the distortion between the intended and the received image of the church.
\end{abstract}

\section{DIE EINTLIKE KERK, DIE ONEINTLIKE KERK EN DIE VERSKIL}

Die destydse epogmakende boek van Hans Küng oor die kerk onderskei in sy openingshoofstuk tussen die eintlike en die oneintlike beeld van die kerk in hierdie wêreld. Omdat die kerk 'n gebeure is, kan die essensie daarvan alleen histories uitgedruk word, maar nooit daarin opgaan nie. Kritiek teen (of bewondering van) die kerk - hoe legitiem dit ook al mag wees - tref slegs die uiterlike, die fasade, van die kerk. Die essensie van die kerk is immers 'n saak van geloof. Sodanige positiewe of negatiewe uitsprake is soos om met die skaduwee van iemand om te gaan - dis eg, maar nie die wesenlike self nie. Dis

\footnotetext{
${ }^{1}$ Voordrag gehou by die opening van die nuwe akademiese jaar voor die Hervormde Teologiese Kollege (HTK) op 4 Februarie 2003 aan die Teologiese Fakulteit van die Universiteit van Pretoria.
} 
nie daar nie, dis hoogstens ook daar! Die onsigbare kerk kan dus slegs van die sigbare kerk onderskei word, maar nooit daarvan geskei word nie. Die kerk se identiteit setel immers in sy veranderlikheid en nie in een of ander botydelike Platoniese idee nie (Küng [1968] 1978:4,13). En omdat die sonde deur die hart van elke gelowige loop, sal die distorsie tussen wat is en wat moet wees, altyd teenwoordig wees. Anders as wat Origines ${ }^{2}$ gesê het, is dit dus beter om te sê dat ons nie in en deur die kerk glo nie, maar ten spyte van die kerk. Tog bly die kerk steeds die ruimte van die gemeenskap van die gelowiges.

Met hierdie paar inleidende opmerkings uit die ekklesiologie oor die dissonansie ten opsigte van die beeld van die kerk, wil ek volstaan. Hoe hierdie distorsie ge ïdentifiseer en in 'n sekere mate geëlimineer kan word, meen ek kan kers by die bestuurswetenskappe ${ }^{3}$ opgesteek gaan word. Dit is boonop my oortuiging dat die gemeente van vandag ook 'n besondere geval van 'n sakeonderneming is. Dit is soms verbasend hoe duidelik en amper resloos sekere sakebeginsels op 'n kerklike situasie van toepassing gemaak kan word. Per slot van rekening is 'n gemeente ook ' $n$ selfstandige stelsel wat met sy eie wigte en teenwigte, in balans moet wees en wat in die samelewing wil oorleef. Die basiese uitganspunt van enige onderneming, naamlik dat dit as oop stelsel in 'n bepaalde omgewing bedrywig is en daar ' $n$ wedersydse afhanklikheid tussen die onderneming en die omgewing bestaan, kan basies net so van die kerk gesê word. Cronjé et al (1991:31) sit die vernaamste doelwitte van 'n onderneming in volgorde van belangrikheid, soos volg uiteen:

- Winsgewendheid

- Groei

- Markaandeel

${ }^{2}$ Extra hanc domum, id est extra ecclesiam nemo salvatur.

${ }^{3}$ Die Praktiese Teologie werk weliswaar ook met hierdie tema. Die bydraes van byvoorbeeld Callahan, Hendriks, Nel e a in hierdie verband is alombekend. Nel (1994) verwys ten opsigte van die "korporatiewe beeld" van die kerk, pertinent na die werk van Snyders (1989) wat vernuwing bepleit in terme van persoonlike, korporatiewe, konseptuele, strukturele en missiologiese dimensies. Tog wil dit blyk dat die korporatiewe kommunikasie t o v identiteit en beeld in die kerk tog nie in die Praktiese Teologie tot sy reg kom nie. 
- Sosiale verantwoordelikheid

- Welstand van werknemers

- Produktiwiteit

- Diens aan verbruikers

Behalwe vir eersgenoemde, sou die lysie mutatis mutandis net so op die kerk oorgedra word. Dalk is ' $\mathrm{n}$ kerk dan duideliker te vergelyk met die ondernemingvorm van 'n Artikel 21 maatskappy wat sonder winsbejag funksioneer. Baie kerklike projekte soos ouetehuise en kinderhuise is dan ook sodanig geregistreer. Die passing op 'n onderneming is dan natuurlik voor die handliggend. 'n Kerk bly egter anders (alhoewel nooit totaal anders nie). Die kerk glo dat hy by grasie van God daar is en deur die lewende God tot bestaan geroep is (HK 21, Vraag en Antwoord 54). Hy vind sy grond dus nie in die natuur nie, maar in die bo-natuur; nie in gewone geboorte nie, maar in wedergeboorte. En omdat dit Gód is wat uit die ganse menslike geslag vir Hom 'n volk byeenroep, het die kerk nie 'n gewoon aardse produk wat hy verkoop nie. Die aksioma van skaarsheid in die ekonomie, t w die verhouding tussen aanbod en aanvraag, vind dus moeilik 'n staanplek in die kerk. Die kerk behoort hom tog nie suiwer in te stel om die behoefte van die mens te probeer peil en dan dienooreenkomstig 'n produk te voorsien wat dit bevredig nie (Bedürfnistheologie). Hy ontvang sy "produk" in die openbaring van God en "verkoop" dit dan aan 'n mensdom wat dit nie wil hê nie! Die behoefte moet dus nie net vervul word nie, maar moet selfs geskep word!

Die kerk lewer in elk geval eerder 'n diens as wat dit 'n produk aanbied (Walker et al 1992:99). Diensorganisasies was aan die einde van die vorige eeu, $75 \%$ van die Amerikaanse ekonomie en het teen ongeveer $4 \%$ per dekade toegeneem (Chase \& Aquilano 1992:113). Diens kan gesien word as, "any activity or benefit that one party can offer to another that is essentially intangible and that does not result in the ownership of anything. Its production may or may not tied to a physical product." (Walker et al 1992:99). Die diens wat die kerk lewer is dus ontasbaar en derhalwe broos. Dit kan maklik tot niet gaan. Dit is so omdat sodanige dienste eintlik op beloftes en versekerings gebaseer is en nie 
regtig gekwantifiseer kan word nie. Daarom sê Walker et al (1992:101) is dit so nodig dat veral diensorganisasies hulle dienste moet koppel aan tasbare sake soos simbole, artefakte, fisiese produkte en mense, as simbole van kwaliteit en integriteit.

Die verskil tussen die eintlike en oneintlike kerk is natuurlik nie net daar vanweë die sonde nie, maar ook vanweë persepsies. Die siening wat die wêreld van die kerk het, sal ook altyd anders wees as wat die gelowiges dit graag wil hê. Die vraag is daarom ook nie of ' $n$ siening reg of verkeerd is nie. Feit is, dit is daar en daarom 'n gegewe. Die resepsie van die boodskap is immers van deurslaggewende belang". Ind (1990:12) sê dan ook dat die "Corporate image is in the eye of the beholder." Dit is maar eers die laaste 2 tot 4 dekades dat maatskappye aandag gee aan die beeld wat hulle uitstraal. Vanselfsprekend moet die bestaande beeld dus nagevors word en aan die bedoelde beeld geyk word. En daarom moet die kerk voortdurend aan sy beeld werk en sorg dra dat dit so getrou moontlik die boodskap wat vir hom belangrik is, kommunikeer.

\section{STRATEGIESE BESTUUR}

Dit kan nie anders as dat allereers uitgemaak word waarheen 'n onderneming op pad wil wees nie. Die strategie is dus altyd die primaat. Visioenêre bestuur beteken dat 'n organisasie word op so 'n manier bestuur dat 'n droom verwesenlik word. Dit moet duidelik wees dat die visie werklik toekomsgeoriënteerd moet wees. Dit moet nie net maar 'n ekstrapolasie van die verlede wees nie. Dan verval mens in die mite van die "ewige wederkeer". Visies bepaal eindpunte en nie beginpunt nie. Net so min mag dit egoïstiese drome wees (Bateman \& Zeithaml 1992:412). Hierdie droom van 'n onderneming kom ook veral van die charismatiese leier af (Charlton 1992:49): "The challenge then facing every leader is to create a vision of the future that beckons each person in the organisation to commit themselves to action."

\footnotetext{
${ }^{4}$ Die klassieke voorbeeld hiervan is dat die drie moontlike standaarde vir videokassete (Philips V2000, Sony Betamax en JVC VHS) die tegnologies swakste - VHS - die mark oorrompel het en die ander net daarby moes inval. Die beeld van die produk, en nie die tegnologie nie, het dus die deurslag gegee.
} 
In die teologie is die toekomsvisie uiteraard die vergesig van die gelowige. Die toekoms is God se toekoms. Hy maak alles nuut (Op 21:5). Jesaja 65:1325 is byvoorbeeld so 'n perikoop waarin die geloofsdroom van 'n profeet na vore kom. In metaforiese en hiperboliese taal word die toekoms in kontras tot die hede beskryf. Die wonder van die toekomstige wêreld is daarin geleë dat dit anders is as die huidige wêreld. Die nood van die hede skep dialekties die idille van die toekoms. Die toekomstige messiaanse ryk bestaan egter nie net uit die idilliese vredestoestand waarin die wolf en die lam saam wei nie; dit kry ook 'n onmiskenbare etiese appèl. In teenstelling met die huidige toedrag van sake sal niemand kwaad aangedoen word nie. Nog so 'n Bybelse voorbeeld is Hebreërs 11 wat weer praat van Abraham wat 'n vergesig gehad het en daarvan geleef het:

Omdat Abraham in God geglo het, was hy gehoorsaam toe God hom geroep het om te gaan na 'n ander land wat sy erfenis sou word. Hy het opgepak en weggetrek sonder om te weet waarnatoe hy eintlik op pad was. Toe hy eindelik aangekom het in die land wat God aan hom beloof het, het hy bly glo, al moes hy in 'n tent woon soos 'n vreemdeling wat geen reg daar het nie.... Hy het die hele tyd uitgesien na die stad wat permanente fondamente het-die hemelse stad wat deur God self ontwerp en gebou is.

Die visie verseker dat die hier en nou oorstyg word. Daarom is Thompson \& Strickland (1987:28) se benadering reg om nie net te vra, "wat is ons besigheid?" nie, maar ook om by te voeg, "Wat gaan ons besigheid wees?". Een of ander tyd, sê hulle, word vandag se antwoorde immers obsoleet. Omdat strategie die korporatiewe identiteit voorafgaan en dus bepaal, is dit uiters belangrik dat die kerk altyd sal vra wat sy eintlike besigheid is, of liewer dan, wat sy besigheid behoort te wees. Dit verseker dat 'n onderneming proaktief, meer nog, kreatief met die werklikheid kan omgaan. Die volgende aanhaling byvoorbeeld van 'n bekende advertensie-maatskappy, illustreer dit (Lascaris \& Lipkin 1993:86): 
At Hunt Lascaris, our stock-in-trade is ideas. That's our raison d' etre. And so our Outside In paradigm is to reach continually and proactively for the big idea that excites our customers and, even more importantly, their customers. And that means constantly renewing and refreshing the appeal of our customers' brands. It means going for the "WOW" factor, that element of "relevant surprise" that transcends the expected to differentiate effectively our customers' brands against competition.

Elke kerk moet dus ook pertinent vra wat sy besondere kompeterende voordeel is. Dít is wat met krag bemark moet word. Kottler (1991:240) noem dit die "unique selling proposition" (USP) van 'n onderneming. As hierdie vraag nie beantwoord is nie, kan differensiasie nie plaasvind nie en kan die ware korporatiewe identiteit en beeld van die kerk ook nie geprofileer, wat sê nog gekommunikeer, word nie.

Daarom moet strategiese bestuur altyd met kompetisie rekening hou. William Porter se model van kompetisie word in alle bestuurshandboeke voorgehou as die standaard (o a Ind 1990:43; Pierce \& Robinson 1991:88; Walker et al 1992:161). Dit hou in dat die onderneming se kompetisie natuurlik primêr bestaan uit die bedreiging van die direkte kompeteerders, maar ook uit die bedreiging wat vier ander magte omvat, $\mathrm{t} w$ die van potensiële toetreders, substituutprodukte of dienste, klante en verskaffers. Die waarde van kompeteerder-analise is dat die standaarde ("benchmarking") van die bedryf geyk kan word en sodoende kan die individuele onderneming sy eie nis maklik identifiseer.

Dit is met taamlike huiwering dat die begrip kompetisie hoegenaamd in kerklike konteks ter sprake gemaak word. Die tradisionele argument sou wees dat gelowiges een in die Here Jesus Christus is (Ef 4) en daarom nie in kompetisie met mekaar is nie, maar eerder as vennote (teen sê maar Satan) te staan kom. Die saak is egter nie so eenvoudig nie. Dikwels is dit standaardpraktyk dat lidmate van een kerk na 'n ander oorgaan. Dit is maar selde dat gemeentes groei deur totaal buitekerklikes te kersten. Een kerk vorm gewoon maar die voedingsbron vir ' $\mathrm{n}$ ander. Met ander woorde kompetisie vind 
net verbloemd in kerklike kringe plaas. Hierdie traagheid om kompetisie in kerklike kringe te erken, sou mens 'n strategiese inersie kon noem.

Dit sal die kerk loon om Edward de Bono (1992) se konsep van sur/petisie in hierdie verband te deurdink. Kom-petisie beteken etimologies om "saam te streef", terwyl sur/petisie beteken om die strewe te transendeer en "bo die lyn" van gemeenskaplike soeke te kom. Daar moet dus verby die voor-diehandliggende sake gekom word soos om "lidmate te wen". Die evolusie van bemarking is dus eerder produksie $\rightarrow$ kompetisie $\rightarrow$ geïntegreerde waardes. Daar word wegbeweeg van die kwantitatiewe ten gunste van die kwalitatiewe. Elke kerk se besondere kompeterende voordeel sal dus hier ter sprake moet kom. Maar soos gesê, dit vra verdere deurdenking.

In 'n baie lesenswaardige boek, Merchants of Vision, gee die redakteur (Liebig 1994), onderhoude weer van 70 uiters suksesvolle sakemanne van regoor die wêreld. Hy noem hierdie leiers profete ("visionaries"). Die saak wat by almal gemeenskaplik is, aldus die bevinding, is elkeen se holistiese fokus op die werklikheid. Ook die geestelike dimensie van menswees binne die grotere netwerk van die skepping, blyk dus konstitutief vir enige besigheid en so vir die samelewing te wees (Liebig 1994:224). En hier lê die uitdaging vir elke kerk in die toekoms! Die kerk moet dus vra wat sy waardetoevoeging tot mens en natuur binne 'n pertinente konteks is ${ }^{5}$.

\section{KORPORATIEWE KULTUUR}

Die manier waarop 'n onderneming se strategie korporatief vergestalt word, noem ons die kultuur van die onderneming. Aangesien ek (Buitendag 2002) elders ook op hierdie aspek van 'n onderneming gewys het, sal enkele opmerkings hier toereikend wees. Kultuur is 'n bepaalde gedrag binne 'n gegewe omgewing en dit word beïnvloed deur waardes, norme en rolle van individue binne daardie omgewing. Kultuur word effektief in terme van Edgar

${ }^{5}$ Wessel Stoker (1993) het in 'n publikasie ook tereg die vraag beredeneer of die vraag na die sin van die lewe, terselfdertyd juis die vraag na God is. Die totale geïntegreerde waarde is dus ter sprake. 
Schein (1999:16) se Drie Vlak -organisasiemodel verduidelik. Op die oppervlakte is dit die duidelikste waarneembaar in die vorm van gewoontes, briefhoofde, verhale, artefakte ensovoorts. Onderliggend hieraan is die betekenisvlak van die gedeelde waardes. En die diepste vlak weer is die onderliggende aannames in terme van ruimte en tyd, fisika en metafisika. Laasgenoemde is uiteraard die moeilikste om te dekodeer en te interpreteer. De Bruyn \& Kruger (1994:179) is op grond van die literatuur ook van oordeel dat daar slegs vier kultuurtipes ${ }^{6}$ bestaan, wat varieer van 'n streng beheerde omgewing tot kreatiwiteit in 'n oop stelsel.

Ondernemings wat suksesvol is, neig om 'n sterk ondernemingskultuur, wat om 'n sentrale stel waardes gebou is, te openbaar en deurtrek elke faset van die onderneming. Ind (1990:11) haal David Mercer aan wat in sy navorsing oor IBM aangetoon het dat dit wat dié magtige organisasie in die snelveranderende samelewing laat oorleef, interessant genoeg nie sy tegnologie is nie, maar sy besondere etiek en kultuur. Daarom is dit van die uiterste belang dat besef moet word dat die korporatiewe beeld bestuur moet word en altyd die uitdrukking van 'n strategiese visie moet wees. Alleen so kan die strategiese visie - gedra deur gedeelde waardes - in die onderneming sinvol gestalte aanneem.

\section{KORPORATIEWE IDENTITEIT}

Korporatiewe identiteit word deur 'n onderneming se geskiedenis, kultuur, mense, leiers, waardes en strategie bepaal. Ind (1990:17) bied die volgende definisie van 'n korporatiewe identiteit aan: "Corporate identity is a powerful tool in the coporate tool kit, which enables you to communicate change, it enables you to communicate direction and it enables you to communicate your point of difference."

Die korporatiewe beeld sal dus sake soos die aard, styl, die besondere kompeterende voordeel, die reliëf in die struktuur en die roete en koers van die onderneming moet kan kommunikeer. Die identiteit word 'n verwysingsraamwerk waarbinne alle aktiwiteite van die onderneming geëvalueer word. Dit beteken

${ }^{6}$ Dit is kwaliteit, kreatiwiteit, produktiwiteit en ondersteuning. 
dus dat die identiteit ook die korporatiewe beeld voorafgaan. Anders gesê, die funksie van 'n korporatiewe identiteit is om daardie fisiese manifestasies te ontwikkel waaruit die kliënte 'n beeld van die onderneming kan opbou én behou. Visuele seine moet dus die omgewing iets vertel van die onderneming self. Gregory (1991:61) formuleer dit raak wanneer hy sê, "In other words, corporate identity is a visual statement of who and what a company is." Hoffman (1991:2930) weer, wil die korporatiewe beeld heelwat meer komprehensief verstaan en saam met die organisasie, ook die produk of diens én die bemarking daarvan insluit. Dit gaan dus om die totale pakkie.

Dit behoort duidelik wees dat selfs as 'n onderneming nie doelbewus poog om sy eie identiteit te vestig nie, dit ongeag sal ontwikkel. Die korporatiewe beeld setel immers ook in die oë van die kliënt. Die ontvangs van die boodskap is dus waarop dit by die korporatiewe beeld aankom. Daarom gaan dit in die korporatiewe beeld nie net om 'n uitdrukking van die identiteit nie, maar veral ook om die identifisering en regstelling van die kommunikatiewe dissonansie daarvan. Hierdie dissonansie moet ook empiries nagevors word. Dit is daarom reg om te stel dat korporatiewe kommunikasie die proses is om korporatiewe identiteit in 'n korporatiewe beeld te vertaal (Ind 1990:15). Daarom sal die kommunikasie-oudit ook voortdurend moet plaasvind ${ }^{7}$.

Kottler (1991:612) gee 'n baie eenvoudige, maar effektiewe, grafiese voorstelling wanneer hy die assessering van die attribute van die korporatiewe beeld, met sy gepaardgaande gaping, soos volg voorstel:

Hoë integriteit
Innoverend
Vriendelik
Kundig
Groot

7 Ind (1990:72-77) stel byvoorbeeld 'n kommunikasie-matriks voor ten einde die kwantitatiewe oordrag van die korporatiewe beeld te peil. Op die horisontale as word al die produkte geplaas en op die vertikale as, die bestaande korporatiewe merkers (soos geboue, kantooruitleg, briefhoofde, visitekaartjies ens). Deur hierdie kruiskontrole kan dan maklik vasgestel word waar leemtes aanwesig is. 
Van die belangrikste merkers hiervoor is seer sekerlik die naam, die slagspreuk, die logo, die grafika en die taal (Ind 1990:140). Met die naam moet besonder omsigtig omgegaan word en as dit enigsins effektief is, is dit raadsaam om dit te behou. Slagspreuke is natuurlik baie tyd en plek gebonde en moet voortdurend hersien en geskep word. Die slagspreuk byvoorbeeld, "Wie moet ons bedank?", van 'n bekende bankgroep, het gou wyd inslag in die SuidAfrikaanse gemeenskap gevind en net so gou ook weer van die toneel verdwyn. Die $\log 0^{8}$ weer, moet as 't ware die fokus van die onderneming vasvang en is uiters belangrik. Nie net moet wat die onderneming doen daarin gereflekteer word nie, maar ook hoe hy dit doen. Die doelmark moet natuurlik ook bepaal word sodat die korrekte seine uitgestuur kan word. Die rol wat kleure hierin speel, is uiteraard van deurslaggewende belang ${ }^{9}$. Grafika en taal word dikwels onderskat. Selfs die lettertipes in korrespondensie is belangrik.

\section{SLOT}

Ek het reeds genoem dat in die korporatiewe kommunikasie-oudit, 'n onderneming ook 'n empiriese ondersoek sal moet loods ten einde (die dissonansie in) sy korporatiewe beeld te bepaal. Ek oordeel dat die kerk dit ook nogal haas dringend sal moet doen. Die volgende twee resente aanhalings uit Beeld, onderskeidelik 'n "Ope Brief aan God" en "Steve se God van Genade", bevestig die erns:

\footnotetext{
${ }^{8}$ Dit is interessant om te sien hoedat die Ned Herv Kerk se kerkwapen spontaan as ' $n$ logo aangewend word (dasse, voorskote, tafelgerei ens), sonder dat dit ooit so bedoel was. Vir 'n insiggewende artikel oor die ontstaan en vestiging van die Ned Herv Kerk se kerkwapen, sien Rex (1982). Dit sou 'n interessante oefening wees om hierdie "logo" aan die Ned Herv Kerk se visie en missie te gaan toets!

9 Pienaar \& Spoelstra (1991:65-66) identifiseer die volgende assosiasies by kleure: blou dra 'n rustige, dog gesagvolle beeld oor; geel word met verloor geïdentifiseer; room is neutraal; grys en bruin is depressief en rooi, wanneer matig gebruik, dra opwinding (maar soms ook vrees) oor. Tog meen die outeurs dat vir bemarkingsdoeleindes in Suid-Afrika, geel met die son vereenselwig word en dus iets van vitaliteit wil sê; groen weer roep assosiasies met vegetasie en natuur op en rooi met opgewondenheid, liefde en ook woede.
} 
Die kerk is korrup. Gewapen met die alleenreg op saligheid en die ewige lewe word onskuldige mense gemanipuleer en onderwerp.... Die kerk is wreed en sonder empatie teenoor die gemeenskap waarin dit geplaas is .... In die wrede wêreld waarin ons leef, word ons verneder deur sinodes wat ons pyn nie ken nie, maar lighartig korswel oor die gebruik van kelkies of bekers vir die nagmaal, of vroue menswaardig genoeg is om ampte te beklee en of homoseksuele enige aanspraak op u koninkryk het.

En:

Weet jy waarvoor is ek bang en waarom kan ek my nie vereenselwig met die gode van die sinode nie? Dit is omdat hulle karikature van Hom gemaak het. Ek sien drie Jesus-karikature. Ek sien die skuim-indie-mond-Bush-tipe karikatuur, ek lees 'n Spaanse-inkwisisie-tipe karikatuur en dan is daar die tipe God van die Sondagskool of kerkamp van die jare 70 . Ek weier om te val vir die karikature. God is te groot vir dit.

Die feit dat hierdie twee artikels soveel openbare reaksie ontlok het, en meesal instemmende reaksie!, moet die kerk tot groot kommer stem. Dit gaan immers om persepsies in die eerste plek en nie om feite nie. (Küng sou kon antwoord dit raak slegs die oneintlike kerk, en nie die eintlike kerk nie). Maar steeds neem dit die erns van die saak of die gebrokenheid van die kerk, nie weg nie. Ook die handelswêreld worstel maar gedurig met persepsies. Vergelyk byvoorbeeld watter indrukke in die verlede van die volgende handelsmerke bestaan het (Van der Walt \& Machado 1992:77):

- 'n BMW eienaar word beskou as 'n opkomende, uitvoerende amptenaar wat in 'n welgestelde voorstad woon en sowel hard werk as hard speel;

- 'n Jaguar eienaar is 'n Engelsman met 'n grys snor, hy het sukses behaal en drink G\&T. Hy is effens geset en is steeds met sy eerste vrou getroud. Hy woon die Rotariërs se vergaderings by; 
- 'n OMO gebruiker is 'n oorgewig middeljarige vrou, woon op die platteland en skryf briewe aan seep-fabrikante oor haar vuil wasgoed;

- 'n Mercedes-Benz eienaar is 'n NNP-lid met ' $n$ ingenieursgraad van Tukkies en 'n MBA van Stellenbosch.

Daarom het BMW toe ook daadwerklik nie net op hulle produk gefokus nie, maar ook op die markposisionering en veral die mark se gesindheid en houding teenoor die produk (Van der Walt \& Machado 1992:81).

Samevattend dus, die kerk moet weer begin droom. 'n Visie moet tot stand kom wat deur almal gedeel word. Sodoende sal 'n identiteit geprofileer word wat kragtig deur korporatiewe kommunikasie uitgebou kan word. Die kerk moet 'n korporatiewe beeld hê wat oordra wat vir ons Bybels belangrik is. Die gemeente se verskillende bedieninge moet ook gesamentlik en afsonderlik, hierdie korporatiewe beeld uitstraal. 'n Beeld waarvan die grond alleen die opgestane Here kan wees. Efesiërs 5:27 se uitdrukking wat praat van die kerk as sonder vlek of rimpel, moet eskatologies verstaan word wat die kerk dinamies op die pad vorentoe plaas. Sonde en heiligheid is dan nie bloot twee sye van dieselfde munt nie, maar ook die verlede en die toekoms van die kerk. Sodoende slaan die indikatief oor in die imperatief. As vierkantige pen in ' $n$ ronde gat in hierdie wêreld - eenders, dog anders - beur die kerk vorentoe met sy vergesig van Jesus wat alles in almal sal wees.

Nee, ek bepleit geensins dat nou oorgegaan moet word na die weg van professionele kerklike 'beeldpoetsers' nie. Inteendeel. Ek pleit vir visioenêre bestuur in die kerk, wat strategies in sy identiteit neerslag vind en wat deur ' $n$ korporatiewe beeld effektief gekommunikeer word. Marksensitiwiteit is dus die woord!

\section{Literatuurverwysings}

Bateman, T S \& Zeithaml, C P 1993. Management: Function \& strategy. Boston: Irwin. Buitendag, J 2002. Postliberale teologie as teologiese raamwerk vir die kerk se korporatiewe identiteit. HTS 58(1), 1-25. 
Charlton, G 1992. Leadership: The human race. Kenwyn: Juta.

Chase, R B \& Aquilano, N J 1992. Production and operations management: A life cycle approach. Boston: Irwin.

Cronjé, G J de J et al 1991. Inleiding tot die bestuurswese. Halfweghuis: Southern.

De Bono, E 1992. Sur/petition: Going beyond competition. London: HarperCollins.

De Bruyn, H E C \& Kruger, S 1994. Strategiese bestuur. Vanderbijlpark: Entrepro.

Gregory, J R 1991. Marketing corporate image. Illinois: NTC Business Books.

Hoffman, J P 1991. Die belangrikheid van 'n korporatiewe beeld vir kleinsakeonderneming op die Transvaalse platteland, 1989. M Com verhandeling, Universiteit van Pretoria, Pretoria.

Ind, N 1990. The corporate image. London: Kogan Page.

Kotler, P \& Armstrong, G 1991. Principles of marketing. New Jersey: Englewood.

Küng, H [1968] 1978. The Church. London: Search Press.

Lascaris, R \& Lipkin, M 1993. Revelling in the wild. Cape Town: Human \& Rousseau.

Liebig, J E (ed) 1994. Merchants of visions: People bringing new purpose and values to business. San Francisco: Berrett-Koehler.

Nel, M 1994. Gemeentebou. Halfweghuis: Orion Uitgewers.

Ope brief aan God. Artikel in Beeld, 13 Januarie 2003. Pretoria.

Pienaar, W \& Spoelstra, M 1991. Negotiations: Theories, strategies and skills. Cape Town: Juta.

Pierce, J A \& Robinson, R B 1991. Formulating, implementation and control of competitive strategy. Boston: Irwin.

Rex, H M 1982. Die kerkseël en -wapen van die Nederduitsch Hervormde Kerk, in Die kerk in die wêreld. Pretoria: Kital.

Schein, E H 1999. The corporate culture: Survival guide. San Francisco: Jossey-Bass.

Snyders, H A 1989. Signs of the spirit: How God reshapes the church. Grand Rapids: Zondervan.

Steve se God van genade. Artikel in Beeld, 16 Januarie 2003. Pretoria.

Stoker, W 1993. Is vragen naar zin vragen naar God? Zoetermeer: Meinema.

Thompson, A A \& Strickland, A J 1987. Strategic management: Concepts and cases.

Texas: Business Publications.

Van der Walt, A \& Machado R 1991. New marketing success stories. Halfway House: Southern Books.

Walker, C W, Boyd, H W \& Larreche, J-C 1992. Marketing strategy: Planning and implementation. Boston: Irwin. 